\title{
Comparison of ELISA with virus isolation for the diagnosis of genital herpes
}

\author{
I ALEXANDER, ${ }^{*}$ CR ASHLEY, $\dagger \mathrm{KJ}$ SMITH, $\ddagger$ J HARBOUR, $\dagger$ APCH ROOME, $\dagger$ \\ JM DARVILLE $\ddagger$
}

From the Departments of *Genito-Urinary Medicine and $\ddagger$ Microbiology, Bristol Royal Infirmary, Bristol, and the Joint Regional Public Health and District Virology Laboratory, Kingsdown, Bristol

SUMMARY An enzyme linked immunosorbent assay (ELISA) system which detects and simultaneously types herpes simplex virus antigens in clinical specimens from patients with genital herpes has been compared with standard tissue culture isolation. Although more sensitive than a similar method previously described and also more sensitive than electron microscopy and immunofluorescence, ELISA did not detect all the viruses isolated in tissue culture. Costs were comparable. The speed of obtaining the result together with knowledge of the type causing infection are useful when antiviral chemotherapy is envisaged and when considering the likelihood of recurrences.

For many years virus culture has been the method of choice for detecting herpes simplex virus (HSV) infections of the genital tract as well as other sites. The virus grows well in a variety of tissue culture systems, including continuous cell lines such as Vero and BHK-21, although diploid human embryo fibroblasts are probably the cells most often used. Tissue culture has, however, a number of disadvantages. Specimens must reach the laboratory in a viable state, and a specialised virus facility must be available. Isolation is relatively slow, taking an average of two to four days, with some specimens containing little infectious virus taking up to five or six days.

The advantages of rapid and sensitive alternatives to culture have been emphasised by numerous workers. In order of increasing sensitivity these techniques include staining of smears by crystal violet and Papanicolau, ${ }^{1}$ electron microscopy, ${ }^{23}$ direct and indirect immunofluorescence, ${ }^{45}$ immunoperoxidase staining, ${ }^{67}$ biotin-avidin enhancement of immunofluorescence, ${ }^{8}$ enzyme linked immunosorbent assay (ELISA),, 10 chemiluminescent ELISA," and, recently, DNA hybridisation. ${ }^{12}$

These techniques have been used in two ways: to detect viral antigens $(a)$ directly in clinical specimens and $(b)$ in inoculated tissue culture after $24 \mathrm{~h}$ incubation. With the second approach detection rates compare well with virus isolation. But although this

Accepted for publication 5 February 1985 speeds up the diagnosis, additional complexity is incurred and the expense of culture is not avoided.

So far no method has been able to detect HSV in all the specimens from which the virus has been isolated. Rates of detection have matched most closely in the examination of vesicle fluid, where electron microscopy compares well with virus isolation. Indeed, electron microscopy is the method of choice in diagnosing HSV infections in immunosuppressed patients, when speed is essential. When later lesions from the same patient are examined, however, the comparison with culture becomes much less favourable.

\section{Material and methods}

PATIENT SELECTION

Specimens were collected from 103 patients attending the Department of Genito-Urinary Medicine, Bristol Royal Infirmary, who presented with blistering or ulcerative lesions of the genitalia. Patients with lesions at an advanced stage of healing and those who had used specific antiviral chemotherapy were excluded. Fifty seven of the 103 patients were diagnosed as having either primary or recurrent $\mathrm{HSV}$ infection on clinical examination. In the remaining patients HSV infection was considered in the differential diagnosis.

\section{SPECIMEN COLLECTION}

Duplicate swabs were taken from suspicious lesions on the penis, perineum, perianal region, vulva, and 
cervix, the swabs being simultaneously rotated in the expressed blister fluid or ulcer. One swab was then broken off into $4 \mathrm{ml}$ of virus transport medium (half skimmed milk and half phosphate buffered saline) for later tissue culture inoculation; the other swab was placed in $0.5 \mathrm{ml}$ of ELISA washing buffer. Initial experiments had shown that the ELISA method was not sensitive enough for material diluted in $4 \mathrm{ml}$ of virus transport medium to be used.

\section{VIRUS ISOLATION}

After collection swabs in transport medium were immediately placed at $4^{\circ} \mathrm{C}$ and stored until later inoculation into tissue culture. This was usually within $3 \mathrm{~h}$ of collection, but specimens from evening clinics were inoculated the next morning. Duplicate tubes of either MRC5 cells or local low passage human embryo fibroblasts were inoculated with $0 \cdot 1$ $\mathrm{ml}$ of transport medium. Cells were maintained rolled at $36-37^{\circ} \mathrm{C}$ in Eagle's medium with $2 \%$ fetal calf serum and were examined daily for cytopathic effect. Typical cytopathic effect was confirmed as being caused by HSV by indirect immunofluorescence using rabbit anti-HSV antiserum and a fluorescein isothiocyanate antirabbit conjugate.

\section{ELISA DETECTION AND TYPING}

The Dakopatts ELISA kit for detecting and typing HSV based on the method of Vestergaard and Jensen was supplied by Mercia Brocades. The details of the technique were as supplied by the makers. The method has been previously described, ${ }^{1314}$ and only the main principles are outlined here, although any minor modifications are described in full.

Polyclonal capture antibodies consisting of purified rabbit immunoglobulin fractions of anti-HSV type 1 , anti-HSV type 2 , or control rabbit immunoglobulin (diluted $1 / 50$ in coating buffer) were coated on to wells in microtitre plates and incubated for $1 \mathrm{~h}$ at room temperature. Test samples were added to the plates, which were then incubated at $4^{\circ} \mathrm{C}$ overnight. The next morning peroxidase conjugated antibody (diluted 1/50 in dilution buffer) homologous with the antibody initially used to coat the well was added. Incubation was for $1 \mathrm{~h}$ at room temperature. Substrate (orthophenylene diamine) was then added, the colour developed at room temperature, and the reaction stopped after $15 \mathrm{~min}$ with sulphuric acid.

The reactions could usually be easily read by eye; a negative reaction gave no colour while a homotypic reaction gave a more intense brown colour than a heterotypic reaction. In this study, however, all readings were carried out by an automatic ELISA reader (Dynatech Model MR580) interfaced with a Superbrain Microcomputer (Intertec
Data Systems) programmed to make calculations to determine whether the specimen was positive and, if so, to determine its type.

The only deviation from the maker's instructions was the incubation of plates with test samples overnight at $4^{\circ} \mathrm{C}$ rather than for $2 \mathrm{~h}$ at room temperature. Previous work had shown that this made no difference to the results. Furthermore, this did not delay the result since specimens were rarely received early enough for processing the same day.

\section{Results}

One hundred and three specimens were tested for the presence of HSV by isolation and by ELISA (Table). All specimens positive by ELISA were also positive by isolation, but seven specimens were positive only by isolation. In other words, of 45 specimens positive by isolation seven were missed by ELISA, which thus had a sensitivity $84.4 \%$ of that of the isolation technique. No specimens which were negative by isolation were positive by ELISA. Of the 38 specimens that were positive by ELISA, 32 were typed as HSV 2 and six as HSV 1.

Results of tests of 103 specimens from patients with genital herpes for the presence of herpes simplex virus by isolation and ELISA

\begin{tabular}{lllr}
\hline & \multicolumn{3}{l}{ Virus isolation } \\
\cline { 2 - 4 } & Positive (\%) & Negative (\%) & Total (\%) \\
\hline ELISA & & & \\
Positive & $38(36 \cdot 9)$ & 0 & $38(36 \cdot 9)$ \\
Negative & $7(6 \cdot 8)$ & $58(56 \cdot 3)$ & $65(63 \cdot 1)$ \\
Total & $45(43 \cdot 7)$ & $58(56 \cdot 3)$ & $103(100)$ \\
\hline
\end{tabular}

\section{Discussion}

This method proved reliable, rapid, and suitable for batch testing large numbers of specimens and is therefore useful when examining material from a genitourinary clinic. Although not as sensitive as culture, it compared favourably with most other rapid methods. Clinicians could ideally expect the correlation with tissue culture to be even higher, but ELISA as currently performed may have reached the limit of its sensitivity. ${ }^{8}$

We found it difficult to place an absolute value on the sensitivity of the ELISA in relation to virus isolation as we were unable to establish any correlation between the amount of infectious virus in a specimen (calculated by the method of Reed and Muench ${ }^{14 a}$ ) and the ELISA result (unpublished observations). This may be due to sampling errors introduced by the need to take separate specimens for virus isolation and ELISA. Alternatively, the finding may be correct, since virus isolation detects 
only infectious virus, whereas ELISA detects virus specific antigens, and the two may not be directly correlated. Indeed, the ratio of infectious virus to total viral antigen is likely to change during the development of a lesion and to differ between primary and recurrent lesions. A separate study is required to clarify this point.

Since no isolation negative specimens were positive by ELISA the question of differentiating between genuine HSV antigens and false positive results did not arise. The method can detect nonviable antigens, however, and therefore a positive ELISA result with negative findings on isolation would not necessarily be false.

An added advantage of the ELISA method is the immediate typing of the virus causing the infection, although, unlike restriction endonuclease analysis, the ELISA test cannot detect intratypic variation and thus is of only limited epidemiological value. Typing is of prognostic value in estimating the likelihood of the recurrence of genital herpes since type 1 infection recurs far less often than type 2 infection $^{15}$ (unpublished observations). Furthermore, it may aid the planning of specific antiviral chemotherapy since HSV 1 is more sensitive than type 2 to a range of antiviral agents. ${ }^{16}$

We found ELISA to be more sensitive in detecting HSV than did Lawrence et $\mathbf{l}^{10}$; there were technical differences between the methods. We used the complete Dakopatts system, in which both capture and enzyme linked detecting antibodies were purified and dialysed polyclonal rabbit antibodies, whereas Lawrence et al used the same capture antibody system but their own human high titre antiHSV antibodies and a labelled antispecies serum for further steps in the detection system. We used a small volume of ELISA buffer as transport medium for our specimen collection, whereas they used $3 \mathrm{ml}$ of transport medium, a step which we had previously modified because we found it insensitive.

A disadvantage of our method was the use of a different collecting medium for ELISA and culture. This was done only because our virus transport medium, milk saline, is turbid and interferes with the ELISA. If ELISA were adopted for routine use then a transport medium suitable for both ELISA and virus isolation would be bovalbumin, used in a volume sufficiently small to prevent dilution of the viral antigen beyond the limit of detection.

The ELISA procedure as described by the manufacturers costs about $£ 1.30$ per test, but we have found that the immunological regents may be further diluted by $1 / 2$ with no reduction in the detection rate of HSV from clinical specimens. The cost of each test can thus easily be reduced to about $65 \mathrm{p}$, which compares favourably with the estimated cost of $£ 1 \cdot 10$ for preparing and maintaining a pair of cell culture tubes for about five days and for confirming the specificity of the cytopathic effect by immunofluorescence.

Because of the added expense and inconvenience of running two tests in parallel, the ELISA is worth adopting only if tissue culture can be abandoned. Nevertheless, it is still advisable to store virus in a viable form should subsequent culture for subtyping by restriction analysis or for antiviral sensitivity testing be necessary.

The method is not suitable for urgent one off specimens (such as swabs from pregnant women near to term suspected of having genital herpes) because of cost and inconvenience; if vesicle fluid is available, electron microscopy remains the method of choice. In later lesions the improvement in sensitivity of immunofluorescence with the arrival of monoclonal antibodies may provide the answer. Furthermore, the availability of such monoclonal antibodies may well render ELISA as sensitive as virus isolation and also ease the differentiation by ELISA of the two serotypes of HSV.

We thank Mercia Brocades for supplying the ELISA kits, Dr A Turner of the Department of Microbiology for the computer program, and the consultants of the Department of Genito-Urinary Medicine for their cooperation.

\section{References}

' Brown ST, Jaffe HW, Akbar Zaidi, et al. Sensitivity and specificity of diagnostic tests for genital infection with herpes virus hominis. Sex Transm Dis 1979;6:10-3.

${ }^{2}$ Smith KO, Melnick J. Recognition and quantitation of herpes virus particles in human vesicular lesions. Science 1962; 137:543-4.

${ }^{3}$ Miller SE, Lang DJ. Rapid diagnosis of herpes simplex infection: Amplification for electron microscopy by short term in vitro replication. Journal of Infection 1982;4:37-41.

${ }^{4}$ Rawls EW. Herpes simplex virus types 1 and 2 and herpes virus simiae. In: Lennette EH, Schmidt NJ, eds. Diagnostic procedures for viral, rickettsial and chlamydial infections. 5th ed. Washington DC: American Public Health Association, 1979:309-73.

${ }^{5}$ Gardner PS, McQuillan J. Rapid virus diagnosis: application of immunofuorescence. 2nd ed. London: Butterworths, 1980.

- Benjamin DR. Use of immunoperoxidase for rapid diagnosis of mucocutaneous herpes simplex virus infection. $J$ Clin Microbiol 1977;6:571-3.

' Moseley RC, Corey L, Benjamin D, Winter C, Remington ML. Comparison of viral isolation, direct immunofluorescence and indirect immunoperoxidase techniques for detection of genital herpes simplex virus infection. J Clin Microbiol 1981; 13:913-8.

${ }^{8}$ Nerurkar LS, Jacob AJ, Madden DL, Sever JL. Detection of genital herpes simplex infections by a tissue culturefluorescent antibody technique with biotin-avidin.J Clin Microbiol 1983;17:149-54. 
${ }^{9}$ Miranda QR, Bailey GD, Fraser AS, Tenoso HJ. Solid phase enzyme immunoassay for herpes simplex virus. $J$ Infect Dis 1977;136 (suppl):5304-10.

${ }^{10}$ Lawrence TG, Budzko DB, Wilcke BW. Detection of herpes simplex virus in clinical specimens by an enzyme linked immunosorbent assay. Am J Clin Pathol 1984;81:339-41.

" Pronovost AD, Baumgarten A, Hsiung GD. Sensitive chemiluminescent enzyme linked immunosorbent assay for quantification of human immunoglobulin $G$ and detection of herpes simplex virus. J Clin Microbiol 1981;13:97-101.

12 Richman DD, Cleveland PH, Redfield DC, Oxman MN, Wahl GM. Rapid viral diagnosis. J Infect Dis 1984;149:298-310.

13 Vestergaard BF, Jensen O. Diagnosis and typing of herpes simplex virus in clinical specimens by the enzyme-linked immunosorbent assay (ELISA). In: Nahmias AJ, Dowdle WR, Schinazi RF, eds. The human herpesviruses. New York: Elsevier, 1981:391-4.

${ }^{14}$ Smith KJ, Ashley CR, Darville JM, Harbour J, Roome APCH.
Comparison of a commercial ELISA system with restriction endonuclease analysis for typing herpes simplex virus. $\mathrm{J}$ Clin Pathol 1984;37:937-41.

14a Reed LJ, Muench $\vec{H}$. A simple method of estimating fifty percent end points. Am J Hyg 1938;27:493-7.

is Reeves WC, Corey L, Adams HG, Vontner L, Holmes KK. Risk of recurrence after first episodes of genital herpes: relation to HSV type and antibody response. $N$ Engl J Med 1981; 305:315-9.

${ }^{16}$ Schaeffer HJ, Beauchamp L, De Miranda P, Elion GB, Bauer DJ, Collins P. 9-(2-hydroxyethoxymethyl) guanine activity against viruses of the herpes group. Nature 1978;272:583-5.

Requests for reprints to: Dr APCH Roome, Consultant Virologist, Joint Regional Public Health and District Virology Laboratory, Myrtle Road, Kingsdown, Bristol BS2 8EL, England. 